\title{
Differences in Mechanisms of Orographic Rainfall over West Sumatra (Case Study: 10 April and 23 April 2004)
}

\section{Wendi Harjupa $^{1}$, Toyoshi Shimomai ${ }^{2}$, Hiroyuki Hashiguchi ${ }^{3}$, Yasushi Fujiyoshi ${ }^{4}$, Masayuki Kawashima ${ }^{4}$}

\footnotetext{
${ }^{1}$ The Center for Atmospheric Science and Technology, LAPAN, Indonesia

${ }^{2}$ Remote Sensing Laboratory, Shimane University, Japan

${ }^{3}$ Research Institute for Sustainable Humanosphere, Kyoto University, Japan

${ }^{4}$ Institute of Low Temperature Science, Hokkaido University, Japan
}

\begin{tabular}{l}
\hline \hline Article Info \\
\hline Article History: \\
Received: January 01, 2021 \\
Revised: February 08, 2021 \\
Accepted: February 10, 2021 \\
\hline Keywords: \\
Orographic rainfall \\
Sumatra \\
CPEA-I \\
MJO \\
\hline
\end{tabular}

\begin{abstract}
Two different mechanisms of orographic rainfall enhancement in West Sumatra were investigated utilizing observed data during the Coupling Processes in the Equatorial Atmosphere (CPEA)-I campaign. The variation of the atmospheric conditions during the campaign was shown by rainfall, surface wind, humidity, and stability index. An X-band Doppler radar captured the atmospheric conditions related to the enhancement of orographic rainfall mechanisms. The dry and less stable atmospheric conditions resulted in the convective type of rainfall. In contrast, the humid and stable atmospheric conditions brought the large-scale rainfall in the mountainous region where the events took place coincided with the inactive and active MJO phases.
\end{abstract}

Copyright $\odot 2021$ Author(s)

Corresponding Author:

Wendi Harjupa

Email: wendi.harjupa@lapan.go.id

\section{INTRODUCTION}

One of the generally known orographic rainfall patterns is usually identified by the presence of rain above mountains in an area perpendicular to the coming wind direction and directly interacting with the ocean, as shown in Figure 1 (Stewart, 2013). Temperature variation during the daytime causes air to flow from the lowlands (from the ocean) to higher areas (mountains). The air is lifted to a higher level when it reaches the mountains. The condensation process occurs so that clouds form and eventually rain is generated. In the daily cycle, the windward mountainous area, which is perpendicular to the wind's direction, and the ocean receives more rain than the area behind the mountains.

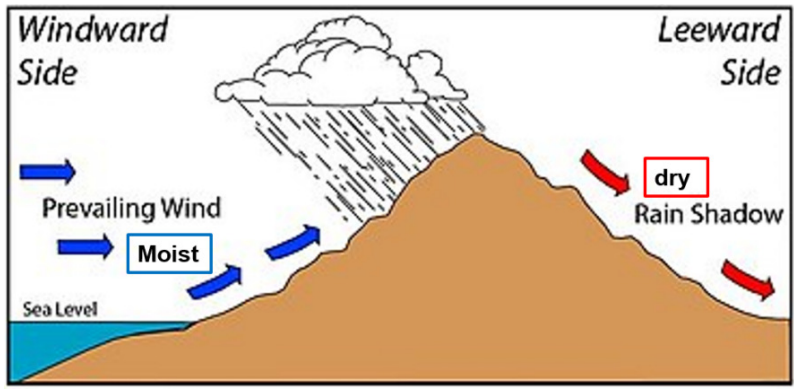

Figure 1. Orographic effect. Adapted from flickr.com by Stewart (2013). 
(a)

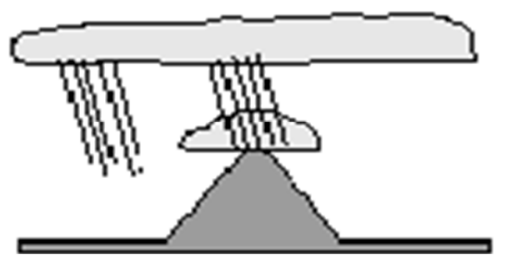

(c)

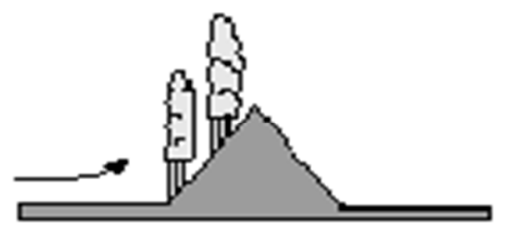

(e)

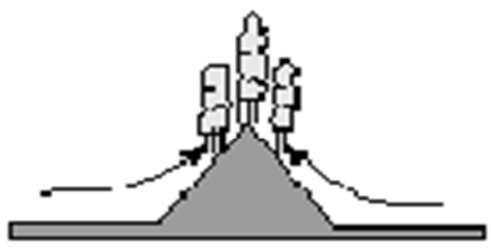

(b)

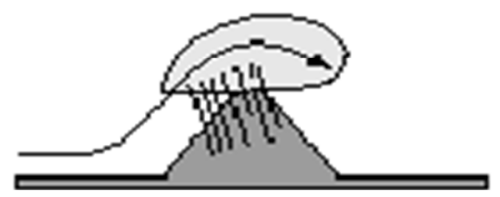

(d)

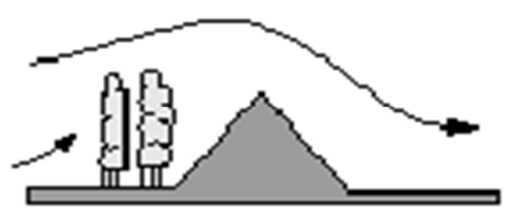

(I)

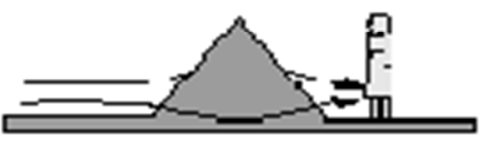

(g)

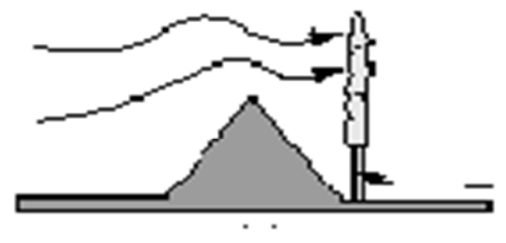

Figure 2. Mechanism of orographic rain formation (a) Seeder-Feeder, (b) upslope condensation/stable upslope ascent, (c) upslope triggering of convection, (d) upstream triggering of convection, (e) thermal triggering of convection, (f) leeside triggering of convection, (g) leeside enhancement of convection (Smith, 1979).

Based on research conducted by Smith $(1979,2006)$, Roe (2005), and Houze and Rotunno (2007), differences in the mechanism of orographic rain formation can cause rain to form not only depend on the windward slopes of mountains facing the ocean but can also occur in the foothills of the mountains and the leeside of the mountains. As is shown in Figure 2 there are some mechanisms for the formation of orographic rain which are named as (a) Seeder-Feeder (rain due to two levels of clouds), (b) upslope condensation (condensation that occurs due to air lifting by hills in the stable condition), (c) upslope triggering of convection (the formed cloud is triggered to be convection due to hills lifting), and (d) upstream triggering of convection (convection at the foot hill). Other types of orographic rain are (e) thermal triggering of convection (convection that occurs due to heating on the slopes of a mountain), (f) leeside triggering of convection (convection caused by leeside slope of mountains), and (g) leeside enhancement of convection (convection reinforced by the slopes behind mountains).

West Sumatra is located at $1^{\circ} 00^{\prime} \mathrm{S} 100^{\circ} 30^{\prime} \mathrm{E}$ in the western part of the island of Sumatra, Indonesia, and this area faces the Indian Ocean. Figure 3a shows a row of hills from northwest to southeast of the Sumatra island, commonly known as "Bukit Barisan" passing through West Sumatra. The topography of West Sumatra is complex and generally consists of mountains; our target area is shown in Figure 3b. Several previous studies have found that "Bukit Barisan" controls the weather in Sumatra. Nitta et al. (1992) show that the propagation of large cloud movements (Super Cloud Cluster; SCC) is blocked by the topography over Sumatra. Shibagaki et al. (2006) found that the effect of Sumatra's topography of the mountain ranges is to block the movement of the western wind (Westerly Wind Burst; WWB). In detail, Kamimera et al. (2012) have explained the connection between the large scale and local topographic effect of Sumatra. 


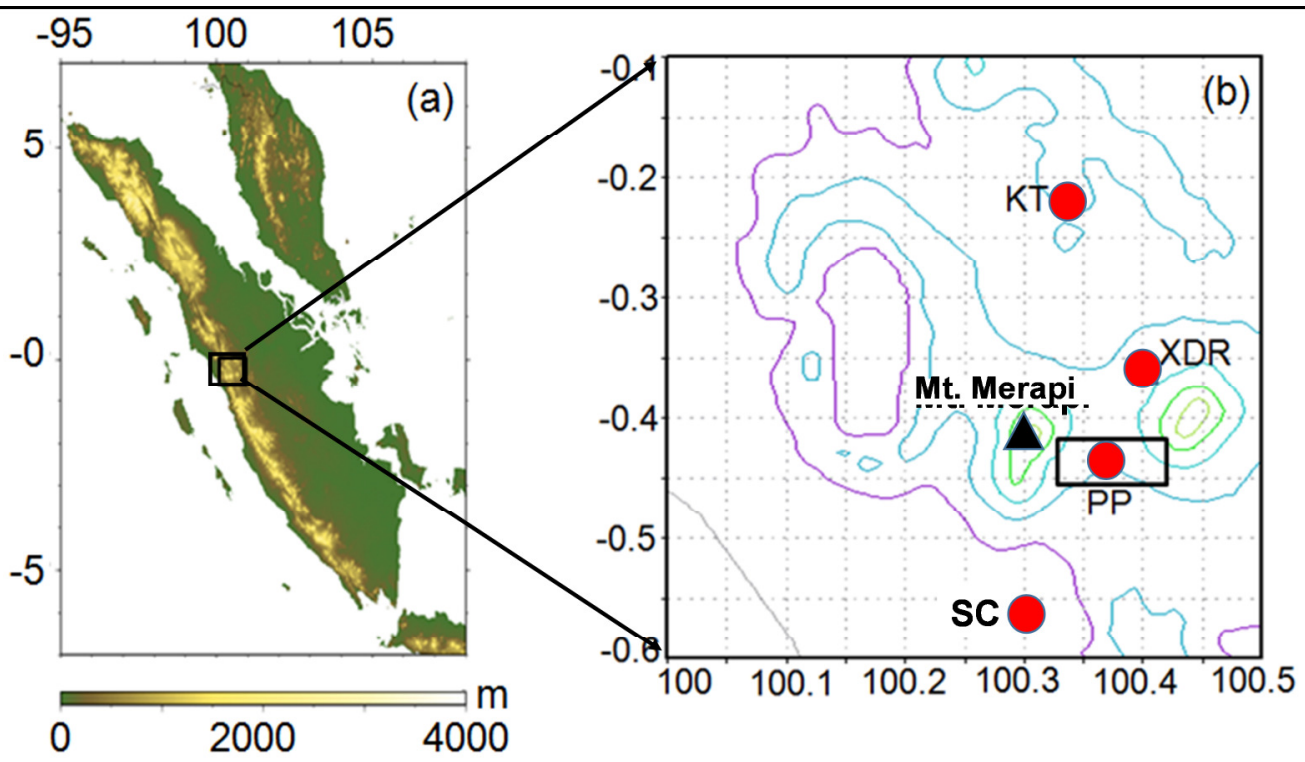

(a)

(b)

Figure 3. (a) The alignment of hills from north to south of Sumatra Island, (b) Research location. KT, PP, SC and XDR denote Kototabang, Padang Panjang, Sicincin, and X-Band Doppler radar, respectively.

The peak of rainfall diurnal cycle (DC) was observed in the afternoon in Sumatra and Siberut Islands by the active modulation of DC and the MJO. However, it is still lacks a clear explanation about diurnal land-sea migration in the mountainous region eventhough Mori et al. (2011) already explained the migration process of coastal convective system. Wu et al. (2008) found the dual rainfall peak in Siberut Island (Western part of Sumatra) and suggested that the increase of moisture during nighttime over Siberut Island might be caused by the water vapor transported from Sumatra Island.

The more recent study about the interconnection between DC and MJO oscillation was proposed by Peatman et al. (2014). The diurnal circulation in the land causes the MJO to move slower, which is different with the movement of MJO in the ocean. The diurnal circulation seems to be more active and modulates the MJO at the beginning of the envelope of MJO. However, wherever the MJO arrives in the land, the DC is suppressed. Lu et al. (2019) proposed a similar study about the impact of MJO circulation to the DC where when the phase of MJO in 2-3 enhances the DC but no effect of MJO in the phase of 6-7.

Based on the previous research, it is very important to research on orographic rain to determine the precipitation mechanism in the mountainous areas of West Sumatra. The modulation between the regional circulation such as MJO and local circulation is very important information to describe the rainfall distribution in the mountainous region. To explain this, Harjupa (2009) has found a relationship between hillside rainfall in the mountainous areas of West Sumatra. The total rainfall in the hilltop area to the west (facing the ocean) of the mountains is higher than in the eastern mountains (rain shadow area).

To determine the process of orographic rain formation in the mountains of West Sumatra this study utilizes the data which was taken from the special observations campaigns for the troposphere called Coupling Processes in the Equatorial Atmosphere (CPEA)-I. The campaign was conducted during March and May in 2004 in West Sumatra, Indonesia (Fukao, 2006). Specifically, we use the information from radars observation, such as X-Band Doppler radar (XDR) and Equatorial Atmosphere Radar (EAR), in this research. We also use the information from sensors such as Automatic Weather Station (AWS) and upper sounding data.

\section{METHOD}

This research emphasizes the usage of XDR data to determine the orographic rain formation mechanism in West Sumatra during the inactive and active phases of the MJO in the CPEA-I observation period. The inactive phase is when the MJO in the phase of 6 and 7, while active phase of 
Harjupa et al.: Differences in Mechanisms of Orographic Rainfall over West Sumatra

MJO is identified by the MJO in the phase 3 and 4 (Wheeler and Hendon, 2004). More details about the data and methods used in this study are described as follows.

\subsection{Location and Data}

The research was carried out in the mountainous area of West Sumatra, as is shown in Figure $3 b$. The data used in this study consists of the rain distribution data from XDR observations, wind profile (speed and direction) from Equatorial Atmosphere Radar (EAR) observations, the rainfall data and surface wind speed observations from Automatic Weather Station (AWS), and the profile of water vapor and temperature taken from radiosonde observations.

\subsection{Data standardization}

Three-dimensional reflectivity data every four minutes were obtained from XDR observations. The sequential scans with antenna elevations from 0.60 to 400 data were interpolated into the Cartesian coordinate system in the horizontal and vertical spatial grid sizes of $500 \mathrm{~m}$ (Kawashima et al., 2006) using the Cressman weighting function. (Cressman, 1959).

In this study, the XDR reflectivity data is plotted by a Constant Altitude Plan Position Indicator (CAPPI) $3 \mathrm{~km}$ above the ground to see the horizontal rainfall distribution. Reflectivity data is also displayed in a vertical cross-section to see rain cloud's height. Observations of the upper atmosphere at 1300 were carried out in Kototabang using radiosonde to obtain information on water vapor and potential temperature. Stable and unstable atmospheric conditions are determined by the Brunt-Väisälä frequency value which is derived from the potential temperature values (Durran and Klemp, 1982). Surface rainfall was analyzed statistically to determine the pattern of rainfall in mountainous areas. Rainfall was obtained from the rain gauges in Sicincin (SC: Figure 3b) and Padang Panjang (PP: Figure 3b).

Equatorial Atmosphere Radar (EAR) is large atmospheric radar that operates at $47.0 \mathrm{MHz}$ with a peak output power of $100 \mathrm{~kW}$. The EAR uses a circular antenna array, approximately $110 \mathrm{~m}$ in diameter and, consisting of 560 three-element Yagi antennas. Each antenna is driven by a solid-state transmitter-receiver module (Fukao et al. 2003). The zonal and meridional wind information from 2 $\mathrm{km}$ to $10 \mathrm{~km}$ taken from EAR was calculated to derive the wind vector information on each altitude.

The XDR information is important information to explain the development and movement of rain in the mountainous area. The rain movement observed by radar is supported by the information of wind profile given by EAR. The rain distribution from the surface at the specific area is given by AWS to confirm the rain distribution obtained by radar observation. The information of stability was calculated from the potential temperature, which can be gained from upper sounding observation. The higher the Brunt-Väisälä frequency, the more stable the atmospheric vertical displacement.

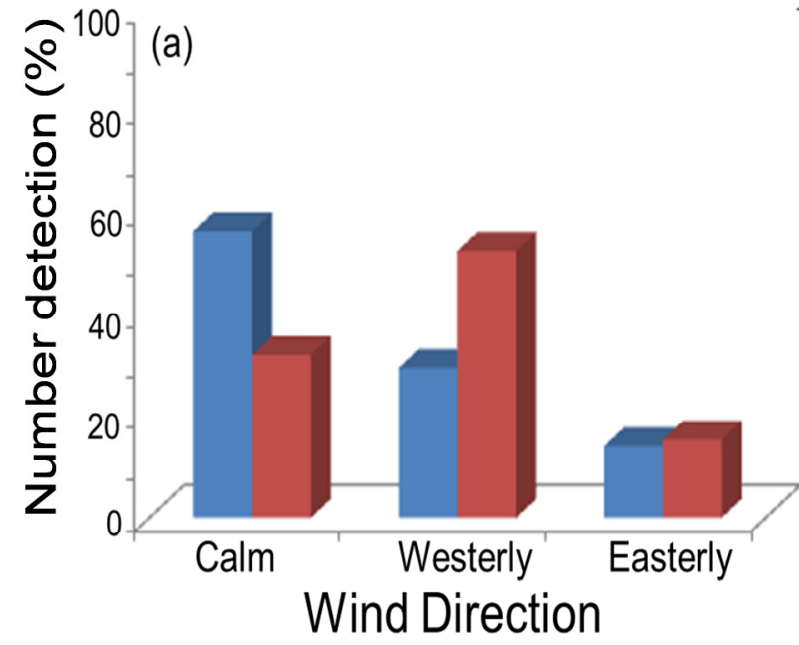

(a)

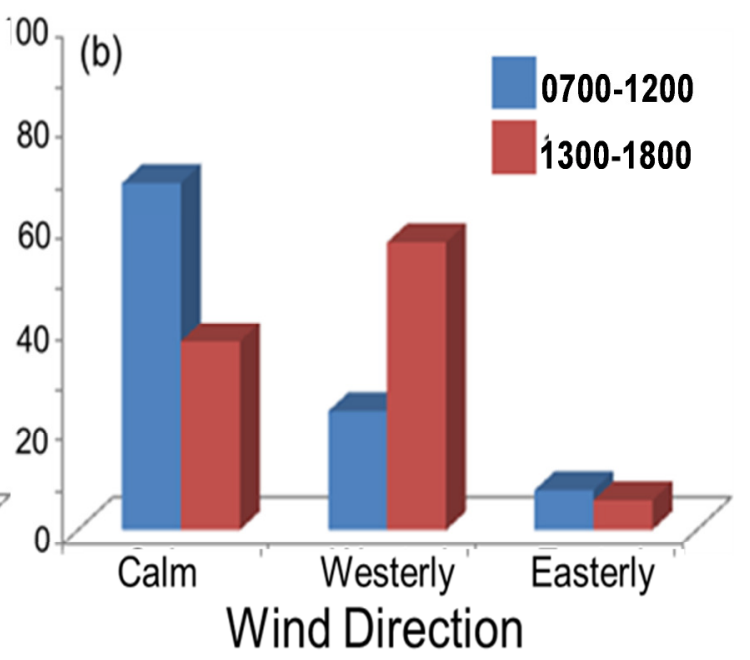

(b)

Figure 4. Wind direction in (a) inactive of MJO, (b) active of MJO phases. 


\section{RESULTS AND DISCUSSION}

\subsection{Surface wind direction}

The surface wind direction detection in SC in the inactive and active phases of MJO is shown in Figures $4 \mathrm{a}$ and $4 \mathrm{~b}$. The surface wind direction is divided into two time periods. The first period is from 0700 to 1200 Western Indonesian Time (all-time uses this time zone in the following), and the second period is from 1300 to 1800 . Surface winds are divided into three categories, namely calm, western and eastern winds. Calm conditions denote when there is no wind movement. Western winds are winds that come from 135 to 315 degrees. East winds are winds that come from 315 to 135 degrees. In the inactive MJO phase, the surface winds in SC are dominated by calm winds, as is shown in Figure 4a. More detection of westerly winds was during 1300 and 1800. The more occurrences of westerly winds may be caused by the temperature difference between the sea and land in the afternoon since the surface temperature in the noon becomes larger than the temperature in the morning. Figure 4a shows that the detection of the easterly wind, both in the periods during 0700 and 1200 and 1300 and 1800 , is not much different.

Figure $4 \mathrm{~b}$ shows the surface wind direction in the active MJO phase. Calm wind conditions were mostly detected in the period between 0700 and 1200. At the same time, at 1300-1800, the number of the occurrence of westerly winds in the active MJO phase is bigger than in the inactive MJO phase. This happened due to the presence of WWB in the active MJO phase. During the presence of WWB in the active MJO phase, more westerly winds were detected than in the inactive MJO phase. WWB has also reduced the presence of the easterly wind, which can be seen in Figure $4 \mathrm{~b}$.

\subsection{Rainfall distribution}

Figure 5 shows the total rainfall in the SC (132 meters above sea level; msl) and PP (728 m msl) areas. The black bar table shows the total rainfall in the inactive MJO phase, while the red bar shows the total rainfall in the active MJO phase. The total rainfall in the SC area in the inactive MJO phase is less than the active MJO phase. In higher areas (PP), the rainfall pattern is different, where the total rainfall in the inactive MJO phase is more than the total active MJO phase rainfall. It can be seen that there is a disturbance in the daily cycle of rainfall in the PP area when the MJO is active or when the WWB is taking place, as is found by Shibagaki (2006). For the SC area in the active MJO phase, it can be seen that the total rainfall is very high.

\subsection{Humidity and Stability}

When the atmosphere becomes humid, it will form wet conditions to produce more precipitable water instead of a dry atmosphere. Differences in atmospheric conditions were detected on April 10 (inactive MJO phase), and April 23, 2004 (active MJO phase) and listed in Table 1. The average of Relative Humidity (RH) in height from $1 \mathrm{~km}$ to $1.5 \mathrm{~km}$ is calculated from radiosonde data at 1300. It shows that the atmospheric conditions in the inactive MJO phase are drier than the active MJO phase, where this condition results in less rainfall. Dry conditions also make the atmosphere more difficult to saturate, so rain occurs in higher areas.

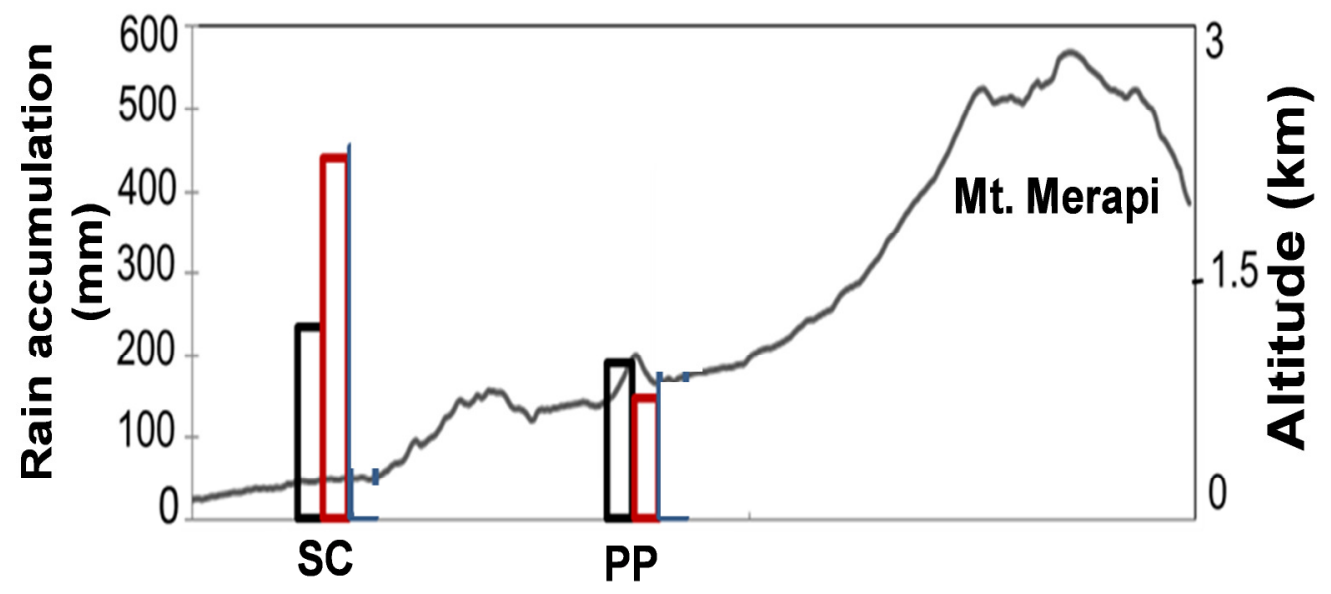

Figure 5. Rainfall accumulation at Sicincin (SC) and Padang Panjang (PP). 


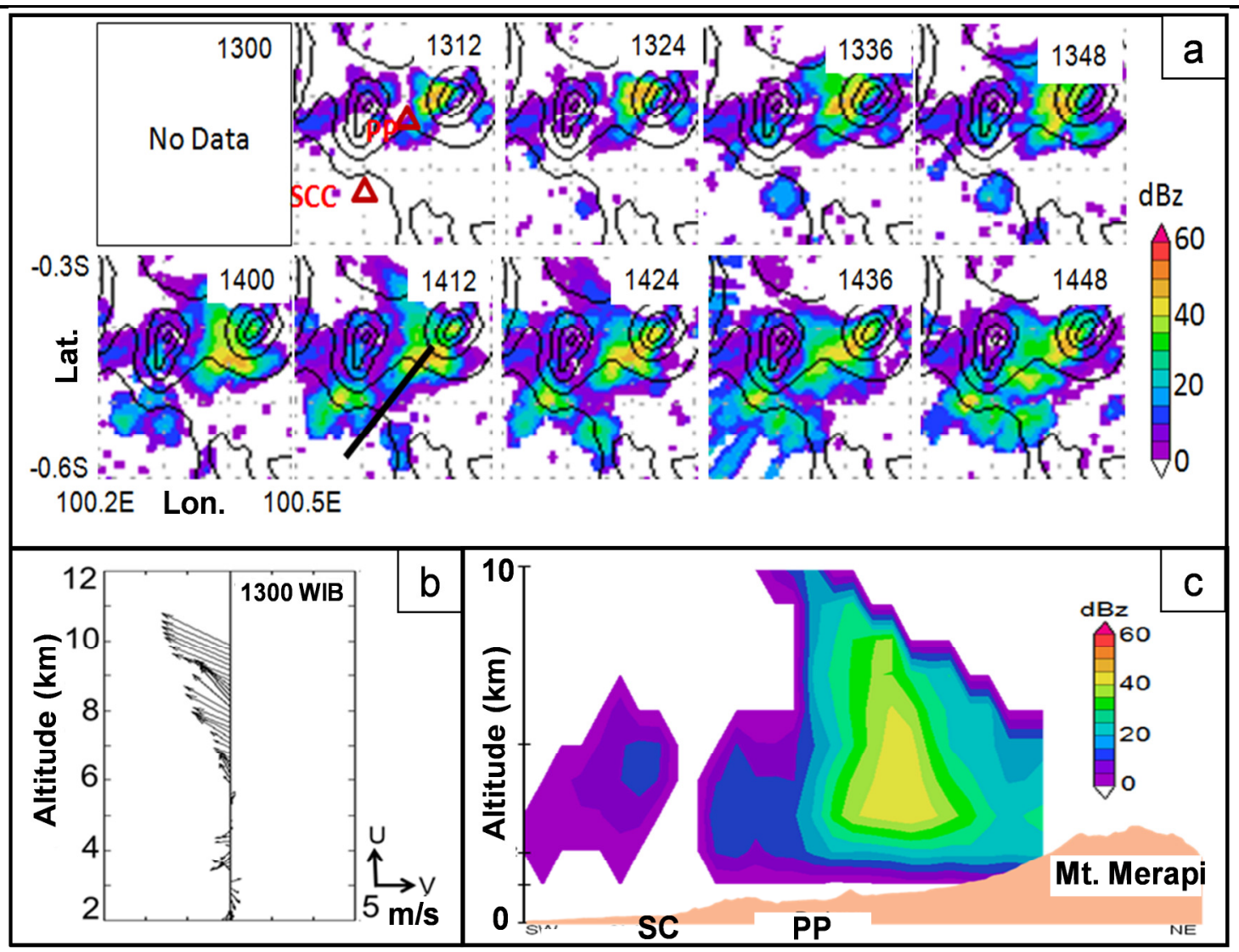

Figure 6. (a) The horizontal distribution of radar reflectivity at $3 \mathrm{~km}$, (b) Wind speed and direction, (c) Vertical cross section of radar reflectivity (slanting line at 1412 at Figure 6a).

The Brunt-Väisälä frequency values at the altitude between 1 and $1.5 \mathrm{~km}$ are taken from the potential temperature values obtained from the radiosonde observation at 1300. A less or negative value of the Brunt-Väisälä frequency on 10 April 2020 indicates unstable atmospheric conditions, where a positive Brunt-Väisälä frequency value on April, 23 indicates stable atmospheric conditions. The more humid the atmospheric condition caused by the huge amount of water vapor during the active MJO phase resulted in the stable atmospheric condition. The huge amount of water vapor could be condensed into the cloud, shielding the ground from solar heating, and suppressing convection. The Brunt-Väisälä frequency values for these two dates are shown in Table 1. When conditions are unstable in the inactive MJO phase, the convection process occurs in the higher slope of the mountain and produces convection type rain, while when MJO is active, atmospheric conditions are more stable.

\subsection{The distribution of Horizontal and Vertical rainfall}

\subsubsection{Inactive of MJO phase (10 April 2004)}

Figure 6a shows the growth and movement of rain clouds in mountainous areas. The large reflectivity value of $40 \mathrm{dBZ}$ appears at 1312 on a slope near the summit of Mt. Merapi. The location of the occurrence of large reflectivity is in the same location with the wind blow. Over time, radar reflectivity spreads over the mountain side and moves towards the southeast.

The reflectivity movement represents the movement of rain to the southeast which is consistent with the wind direction in the upper atmosphere observed by EAR. The wind speed direction profile from EAR observations is shown in Figure $6 \mathrm{~b}$. The wind speed reached $10 \mathrm{~m} / \mathrm{s}$ at the altitude of $10 \mathrm{~km}$. The wind directions at the top and bottom are different where the wind with a weaker speed moves in many directions. The weaker westerly wind was detected at the lower level from about $2 \mathrm{~km}$ to $3 \mathrm{~km}$. 
Harjupa et al.: Differences in Mechanisms of Orographic Rainfall over West Sumatra

\begin{tabular}{ccc}
\multicolumn{3}{c}{ Table 1. Relative Humidity $(\mathrm{RH})$ and Brunt-Väisälä frequency } \\
\hline Date & Relative Humidity $(\mathrm{RH})(\%)$ & Brunt-Väisälä frequency $\left(\mathbf{N}^{2}\right)$ \\
\hline 10 April 2004 & 72 & $-0.125 \times 10^{-4} \mathrm{~s}^{-2}$ \\
23 April 2004 & 83 & $0.007 \times 10^{-4} \mathrm{~s}^{-2}$ \\
\hline
\end{tabular}

The vertical sections of the reflectivity data are shown in Figure 6c. The vertical section crossing from the southwest to the northeast is shown by the transverse lines in Figure 6a (1412). This shows the formation and growth of rain on the slopes of Mt. Merapi. Convection type rain occurs on slopes with a reflectivity approaching $40 \mathrm{dBZ}$. Rain clouds are produced by cumulonimbus clouds and heavy rain on the higher slope of mountains.

\subsubsection{Active of MJO phase (23 April 2004)}

The radar reflectivity data plotted along with the topography is shown in Figure 7a. It can be seen that the rain with reflectivity less than $40 \mathrm{dBZ}$ is formed over larger areas in the foothills. Rain clouds moved from the southwest to the northeast and passed through the PP area. The reflectivity value increases at higher areas, and was in the values between 1636 and 1648. It is the indication of the enhancement of mountain, where the cloud is lifted up over higher slopes. At the end, the rain cloud was moving westward as it is detected by the radar reflectivity.

The vertical wind profile from the EAR observations is shown in Figure 7b, which shows the observed wind direction in the upper layer from the EAR. The wind was directed to the westward at the speed of $10 \mathrm{~m} / \mathrm{s}$. This corresponds to the movement of rain clouds monitored by radars. The occurrence of WWB can be seen in the Figure 7b, when the westerly wind speed in the lower level from $2 \mathrm{~km}$ to $3 \mathrm{~km}$ in the period of active MJO phase is faster than the westerly wind speed in the inactive of MJO phase.

The vertical cross section of radar reflectivity is shown in Figure 7c. Rain clouds were observed that they were extended from the southwest to the northeast (black line across Figure 7a). This figure also shows an increase of reflectivity in a higher area.

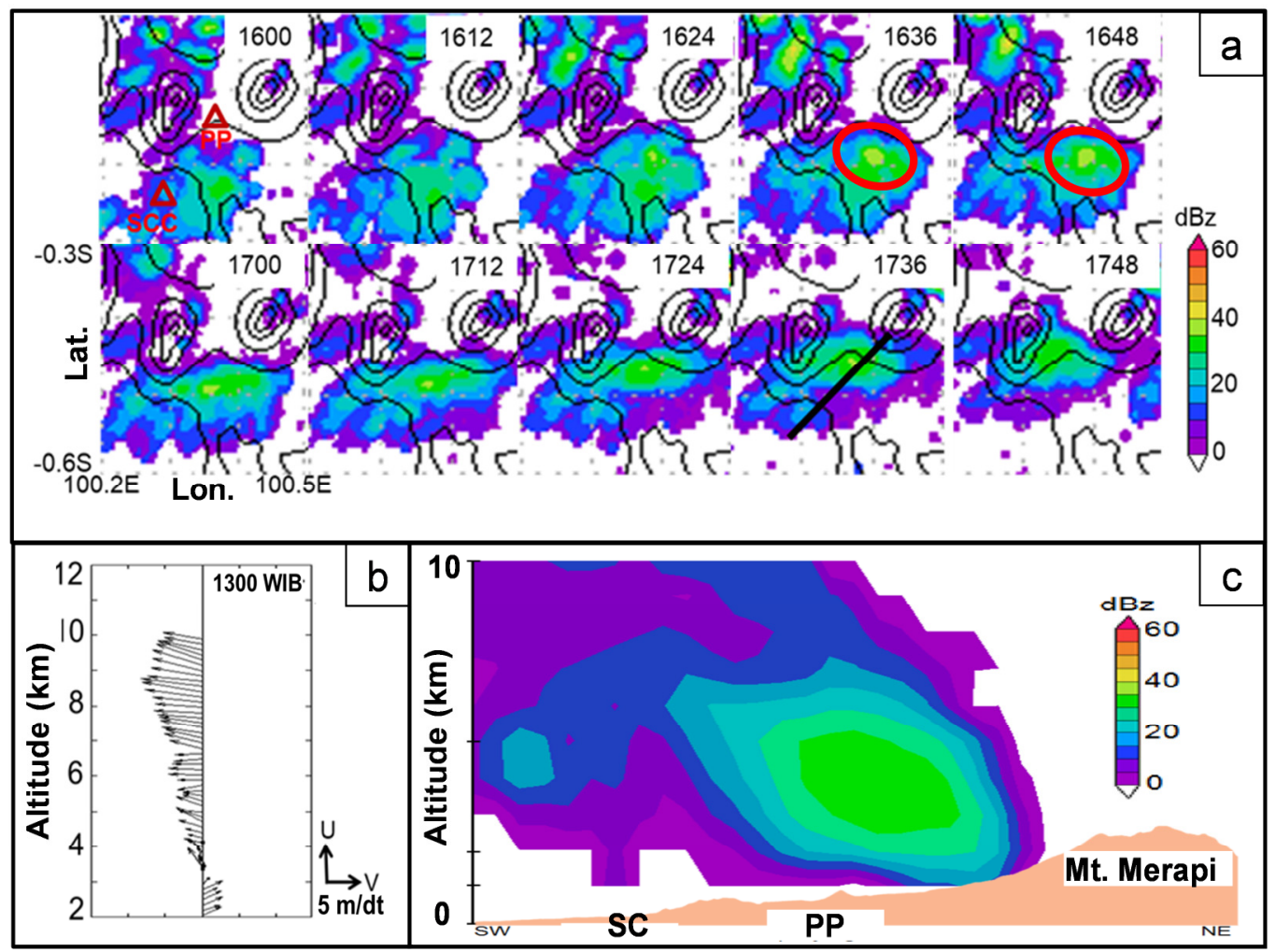

Figure 7. (a) The horizontal distribution of radar reflectivity at $3 \mathrm{~km}$, (b) Wind speed and direction, (c) Vertical cross section of radar reflectivity (slanting line at 1412 at Figure 7a). 

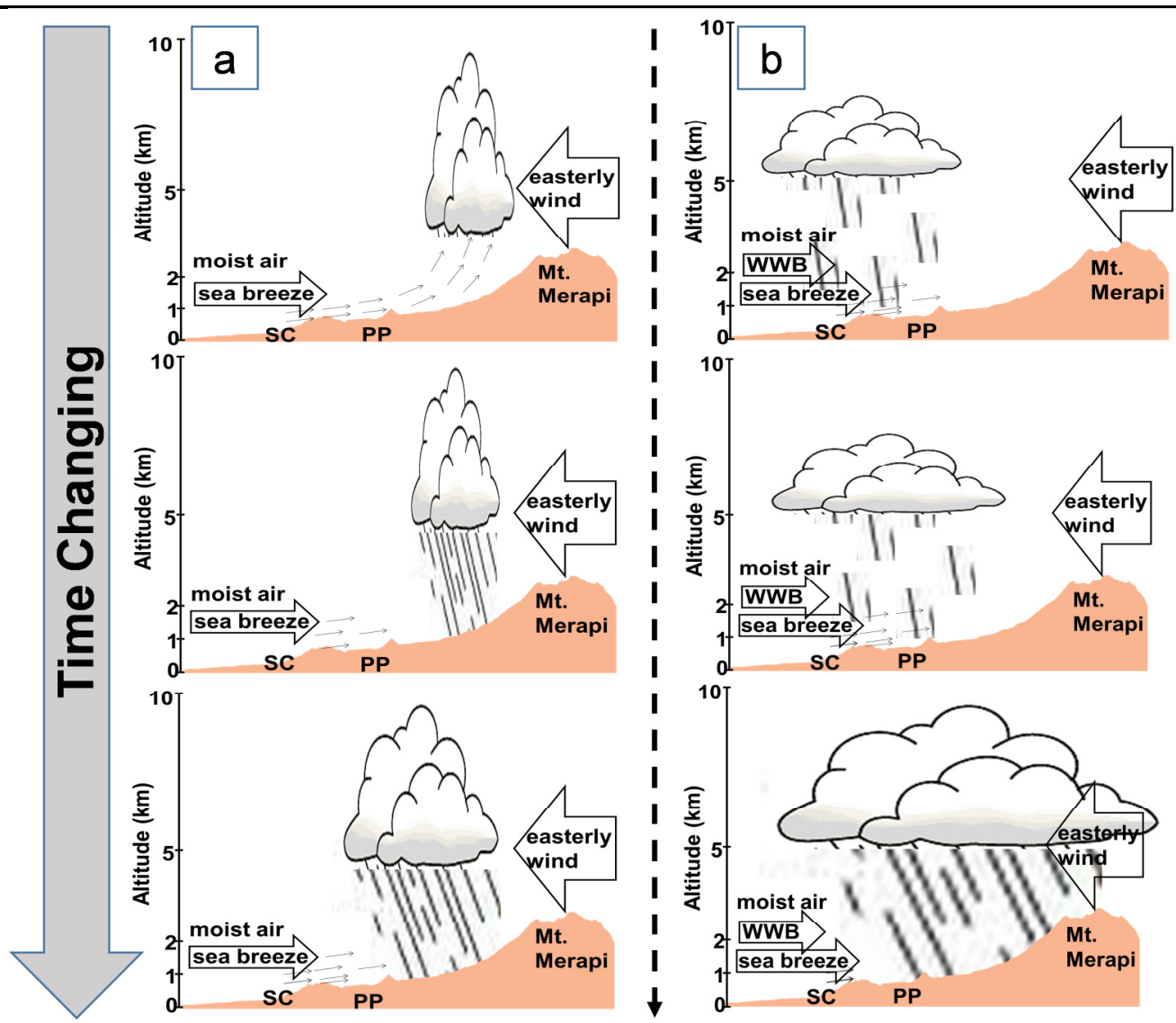

Figure 8. The illustration of orographic enhancement mechanisms on (a) 10 April 2004, and (b) 23 April 2004

\subsection{The illustration of orographic rainfall}

The mechanism of orographic rain formation on 10 April 2004 in the inactive MJO phase is upslope triggering of convection, where the rainfall occur in the higher elevation of mountain. A schematic figure of the forming process is shown in Figure 8a. The sea breeze moving towards the mountains is blocked by the mountain ranges. The air lifted at the free convection level results in condensation on the higher mountain slopes. The area where the rain occurred is in the higher elevation than PP area. The instability of the atmosphere produced the convection and was developed to be a cumulonimbus cloud. The cloud grew to the height of $10 \mathrm{~km}$ as shown in Figure $6 \mathrm{c}$. The dry air of the atmosphere caused the rain to generate in higher areas. The appearance of the eastern wind on the upper layer caused the rain to move westward and pass through the PP area.

Figure $8 \mathrm{~b}$ shows an illustration of development mechanism of orographic rain on 23 April 2004. During the active of MJO phase, the atmosphere was more humid and stable. Rain occurred over a wider area moving from the lower areas of the mountains to the higher areas. The mechanism of the rain occurred is the type of "upslope condensation/stable upslope ascent" where heavier rain occurs because of the uplifting by the higher slopes of the mountains. Due to the WWB, rain can pass through the top of the mountain and occurs in the area behind the mountain (rain shadow area).

\section{CONCLUSION}

This study is performed to investigate the mechanism of orographic rainfall formation that occurred during the CPEA-I observation period in the mountainous area of West Sumatra. Based on the analysis for two cases with different atmospheric conditions, we could conclude:

a. The orographic rain mechanism when atmospheric conditions are less stable is thought to be "upslope triggering of convection." When atmospheric conditions are less stable, and with dry atmospheric conditions, this condition will produce the convection type rain on the higher slopes of mountains (PP area). 
Harjupa et al.: Differences in Mechanisms of Orographic Rainfall over West Sumatra

b. The mechanism for forming orographic rain in stable atmospheric conditions is the "stable upslope ascent" mechanism. When the atmosphere is stable, and with higher humidity or a lot of water vapor at the same time, rain would appear in the lower areas (SC area). The rain is enhanced in the higher slope due to the lifting.

c. The WWB presence during active MJO phase causes rain to reach the eastern mountainous area and produces more rain in the eastern area (rain shadow area). The occurrence of WWB can be used as critical information to the mitigation of rainfall disasters for the public who lives on the leeward sides of mountains.

\section{ACKNOWLEDGEMENT}

The author would like to thank the Japanese government for the research funding given by the Ministry of Education, Culture, Sports, Science and Technology (MEXT). Thank you also to the editorial team of the Jurnal Ilmu Fisika (JIF) and three anonymous reviewers.

\section{REFERENCE}

Cressman, G.P., (1959). An operational objective analysis scheme. Mon. Wea. Rev., 87, 367-374, http://doi.org/10.1175/1520-0493(1959)087<0367:AOOAS>2.0.CO;2.

Durran, D., \& Klemp, J. B. (1982). On the effects of moisture on the Brunt-Väisälä frequency. Journal Of The Atmospheric Sciences, 39, 2152-2158, http://10.1175/1520-0469(1982)039<2152:OTEOMO>2.0.CO;2

Fukao, S., (2006). Coupling processes in the equatorial atmosphere (CPEA): A project overview. J. Meteor. Soc. Japan, 84A, pp. 1-18, https://doi.org/10.2151/jmsj.84A.1.

Fukao, S., H. Hashiguchi, M. Yamamoto, T. Tsuda, T. Nakamura, M.K. Yamamoto, T. Sato, M. Hagio, and Y. Yabugaki, (2003). Equatorial atmosphere radar (EAR): System description and first results. Radio Sci., 38(3), 1053, http://doi.org/10.1029/2002RS002767.

Harjupa, W., (2009). The Development of rain and cloud in the mountainous region of West Sumatra. Proceedings of SNSAA. ISBN: 978-979-1458-78. (in Bahasa)

Houze, R. A., and R. Rotunno, (2007). Lessons on orographic precipitation from the Mesoscale Alpine Program. Q. J. R. Meteorol. Soc., 133, 811-830, https://doi.org/10.1002/qj.67.

Kamimera, H., S. Mori, M. D. Yamanaka, F. Syamsudin, (2012). Modulation of Diurnal rainfall Cycle by the Madden-Julian Oscillation Based on One-Year Continuous Observations with a Meteorological Radar in West Sumatra, SOLA, 8, 111-114, https://doi.org/10.2151/sola.2012-028.

Kawashima, M., Y. Fujiyoshi, M. Ohi, T. Honda, T. Kozu, T. Shimomai, and H. Hashiguchi, (2006). Overview of Doppler radar observations of precipitating cloud systems in Sumatra Island. J. Meteor. Soc. Japan, 84A, 33-56, https://doi.org/10.2151/jmsj.84A.33.

Lu, J. H., T. Li, and L. Wang, (2019). Precipitation diurnal cycle over the Maritime Continent modulated by the MJO. Climate Dyn., 53, 6489-6501. https://doi.org/10.1007/s00382-019-04941-8.

Mori, S., J.-I. Hamada, N. Sakurai, H. Fudeyasu, M. Kawashima, H. Hashiguchi, F. Syamsudin, A. A. Arbain, R. Sulistyowati, J. Matsumoto, and M. D Yamanaka, (2011). Convective systems developed along the coastline of Sumatra Island, Indonesia, observed with an X-band Doppler radar during the HARIMAU2006 campaign. J. Meteor. Soc., Japan, 89 A, 61-81, https://doi.org/10.2151/jmsj.2011A04.

Nitta, T., T. Mizuno, and K. Takahashi, (1992). Multiscale convective systems during the initial phase of the 1986/87 El Nino. J. Meteorol. Soc., Japan, 70, 447 - 466, https://doi.org/10.2151/jmsj1965.70.1B_447.

Peatman, S. C., Mattthews A. J., Stevens, D. P., (2014). Propagation of the Madden-Julian Oscillation through the Maritime Continent and scale interaction with the diurnal cycle of precipitation. Q. J.R. Meteorol. Soc., 140: 814-825, https://doi.org/10.1002/qj.2161.

Roe, G. H., (2005). Orographic Precipitation. Annu. Rev. Earth Planet. Sci, 33, 645-671, https://doi.org/10.1007/978-90-481-2642-2_380.

Shibagaki, Y., T. Kozu, T. Shimomai, S. Mori, F. Murata, Y. Fujiyoshi, H. Hashiguchi, and S. Fukao, (2006). Evolution of a super cloud cluster and the associated wind fields observed over the Indonesian Maritime Continent during the first CPEA campaign. J. Meteorol. Soc. Jpn., 84A, 19 31, https://doi.org/10.2151/jmsj.84A.19.

Smith, R. B., (1979). The influence of mountains on the atmosphere. Adv. Geophys., 21, 87-230, https://doi.org/10.1016/S0065-2687(08)60262-9. 
Harjupa et al.: Differences in Mechanisms of Orographic Rainfall over West Sumatra

Smith, R. B., (2006). Progress on the theory of orographic precipitation, Tectonics, Climate, and Landscape Evolution: GSA Special Paper 398. Boulder: Geol. Soc. Am. Bull., 1-16, https://doi.org/10.1130/2006.2398(01).

Stewart, M., (2013). Orographic Effect. Retrieved from https://www.flickr.com/photos/megstewart/8644087724.

Wheeler, M. C., and H. H. Hendon, (2004). An all-season real-time multivariate MJO index: Development of an index for monitoring and prediction. Mon. Wea. Rev., 132, 1917-1932, http://doi.org/10.1175/15200493(2004)132<1917:AARMMI>2.0.CO;2

Wu, P., S. Mori, J.-I. Hamada, M. D. Yamanaka, J. Matsumoto, and F. Kimura, (2008). Diurnal Variation of Rainfall and precipitable water over Siberut Island off wester coast of Sumatra Island. SOLA., 4, 125128, https://doi.org/10.2151/sola.2008-032 